\title{
Lessons from scaling up a depression treatment program in primary care in Chile
}

\author{
Ricardo Araya, ${ }^{1}$ Rubén Alvarado, ${ }^{2}$ Rodrigo Sepúlveda, ${ }^{2}$ \\ and Graciela Rojas ${ }^{3}$
}

Suggested citation

Araya R, Alvarado R, Sepúlveda R, Rojas G. Lessons from scaling up a depression treatment program in primary care in Chile. Rev Panam Salud Publica. 2012;32(3):234-40.

\begin{abstract}
In Chile, the National Depression Detection and Treatment Program (Programa Nacional de Diagnóstico y Tratamiento de la Depresión, PNDTD) in primary care is a rare example of an evidence-based mental health program that was scaled up to the national level in a low-or middle-income country. This retrospective qualitative study aimed to better understand how policymakers made the decision to scale up mental health services to the national level, and to explore the elements, contexts, and processes that facilitated the decision to implement and sustain PNDTD. In-depth semistructured interviews with six key informants selected through intentional sampling were conducted in August-December 2008. Interviewees were senior officers at the Ministry of Health who were directly involved in the decision to scale up the program.

Results yielded four elements pivotal to the decisionmaking process: scientific evidence, teamwork and leadership, strategic alliances, and program institutionalization. Each element contributed to building consensus, securing funding, attracting resources, and gaining lasting support from policymakers. Additionally, a review of available documentation led the authors to consider sociopolitical context and use of the media to be important factors.

While research evidence for the effectiveness of mental health services in the primary care setting continues to accumulate, low-and middle-income countries should get started on the lengthy process of scaling up by incorporating the elements that led to decisionmaking and implementation of the PNDTD in Chile.
\end{abstract}

Key words Community mental health services; depression; delivery of health care; mental health; Chile.

Coverage by mental health services in Low- and Middle-Income Countries (LMIC) is poor (1). In spite of international calls for scaling up mental health services, the reality on the ground remains disappointing (2). There is no con-

\footnotetext{
1 School of Social and Community Medicine, University of Bristol, Cotham Hill Bristol, United Kingdom. Send correspondence to: Ricardo Araya, email: r.araya@bris.ac.uk

2 Escuela de Salud Pública, Facultad de Medicina, Universidad de Chile, Santiago, Chile.

3 Hospital Clínico, Facultad de Medicina, Universidad de Chile, Santiago, Chile.
}

sensus, but most definitions of "scaling up" comprise an increased supply of services, which ideally should be built on a scientific evidence-base and be sustainable over time (3). A recent systematic review of the literature on scaling up mental health services in LMIC found more than 100 papers (4), but no concrete examples of scaling up strictly as defined above. Despite a few successful trials (5-8), there are no previous examples of an evidence-based mental health intervention being scaled up in any LMIC.
In Chile, the National Depression Detection and Treatment Program (Programa Nacional de Diagnóstico y Tratamiento de la Depresión, PNDTD) in primary care is the first program of this kind established in any LMIC. PNDTD was introduced in 2001 and became a national program in 2003 (9). The program functions within a primary care network that encompasses more than 500 primary care centers throughout the country. Each of these centers has a general clinical team composed of 
BOX 1. Clinical program summary for the National Depression Detection and Treatment Program (Programa Nacional de Diagnóstico y Tratamiento de la Depresión) in primary care, Chile

This program aims to improve the detection and treatment of depressive disorders. Any member of the primary care team can detect and refer a potential case of depression to the program.

- Referrals are seen by General Practitioners and/or Psychologists who confirm the diagnosis according to ICD-10a criteria; assess the severity of symptoms and psychosocial risk factors; and, if required, enroll the person in the program.

- If depression is severe, the person is referred to a mental health specialized unit for a psychiatric assessment ( $7 \%$ of cases).

- If depression is of moderate or mild severity, the person is seen and followed up in the primary care setting according to pre-established clinical guidelines that include frequent consultations and assessments, individual or group therapy, and psychotropic medication, as needed.

- If follow up assessments show little progress or clinical deterioration, a joint assessment by a team leader and a psychiatrist is undertaken and adjustments to treatment are made.

- Patients responding well to treatment are followed up for at least 6 months before discharge.

a World Health Organization. International Classification of Disease, 10th edition. Geneva: WHO; 1990.

FIGURE 1. Number of people receiving treatment through the National Depression Detection and Treatment Program (Programa Nacional de Diagnóstico y Tratamiento de la Depresión) in primary care, Chile, 2001-2007

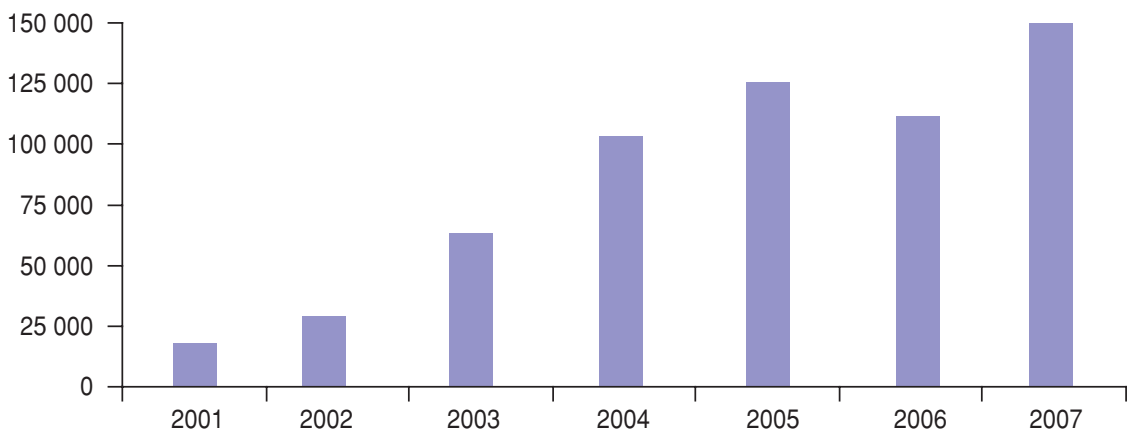

primary care doctors, nurses, and auxiliary nurses. PNDTD offers improved case identification, timely and adequate treatment, and closely monitored follow up for all enrolled cases. The clinical guidelines are similar to those tested in previous trials (8), with the addition of individual therapy and supervision by a specialist for the most severe cases (Box 1 ). PNDTD has been growing steadily, with more than 170000 patients starting treatment in 2007 (Figure 1) and a growing budget that hit US\$ 6 million in 2005. PNDTD is currently a well-established primary care program, sitting comfortably with more traditional programs that manage diabetes and hypertension.

The principal aim of this paper was to conduct a qualitative study to better understand how policymakers made the decision to scale up mental health services to the national level, and to explore the elements, contexts, and processes that facilitated the decision to implement and sustain PNDTD. This is a rare example of scaling up in mental health, and therefore, a unique opportunity to learn more about how decisions of scaling up are made, something that should be relevant to other groups or countries interested in developing similar policies.

\section{MATERIALS AND METHODS}

A retrospective qualitative study was undertaken to reconstruct the elements and context leading to the introduction of the PNDTD in Chile. In-depth, semistructured interviews were held with six key informants selected through an intentional sampling aiming to identify key actors in this process. All interviewees were professionals holding important posts at the Ministry of Health during the process leading to the scaling up of the PNDTD (Figure 2). Four were psychiatrists, of whom one was the former Head of the Mental Health Unit; the second is its current Head, who also led the program design effort; the third was a senior member of the same unit; and the fourth was the Head of the Ministe- rial Cabinet. The fifth interviewee was a public health specialist and Head of the $\mathrm{MoH}$ Primary Care Division, and the sixth, a psychologist responsible for PNDTD implementation. All were interviewed by one of the authors (RS) in August-December 2008. The topic guide used for the interviews is presented in Box 2. All interviews were digitally recorded and transcribed.

Following the interviews, a content analysis (10) was undertaken by RS, who had not participated in designing the study. Other authors helped with validation as second coders. A systematic process of coding and categorization was performed. First, emerging contents were identified, systematized, and assessed in terms of pertinence to the study objectives. Then, a process involving triangulation was undertaken to validate emerging themes. The triangulation involved information gathered from the interviews, available documentation, and revisions by the study's three other authors, a procedure widely accepted in social science research (11). All data analysis was done with ATLAS.ti ${ }^{\mathrm{TM}} 5.2$ (ATLAS.ti Scientific Software Development $\mathrm{GmbH}$, Berlin, Germany). Written informed consent had been obtained from all the interviewees.

\section{RESULTS}

Four critical elements were identified in the process of scaling up PNDTD: 1. scientific evidence; 2. teamwork and leadership; 3. strategic alliances; and 4. program institutionalization. The main results are summarized in Box 3.

\section{Scientific evidence}

All interviewees agreed that in the early 1990s, scientific evidence was insufficient to justify the introduction of a depression treatment program. However, they mentioned that anecdotal reports of successful, small-scale initiatives in primary care were used to support the early stages of the program.

All interviewees agreed that a national disease-burden study conducted in the early 1990s (12), which highlighted the enormous health load associated with depression in Chile, was critical to the introduction of PNDTD. Most previous evidence had been based on mortality statistics, which failed to capture the true burden of chronic and disabling mental 
FIGURE 2. Flowchart of Ministry of Health posts held by the six interviewees involved in the decision to scale up mental health services to form the National Depression Detection and Treatment Program (Programa Nacional de Diagnóstico y Tratamiento de la Depresión) in primary care, Chile, November 2008

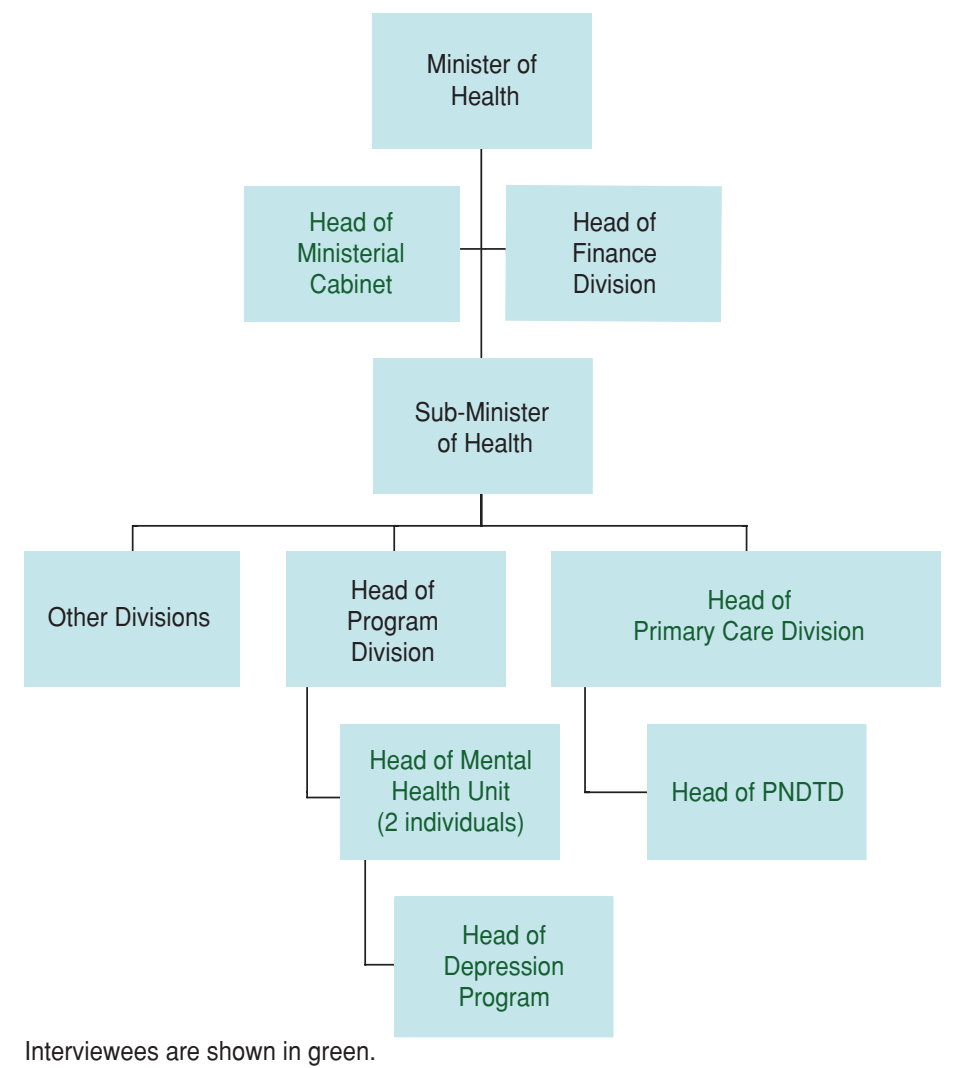

BOX 2. Topic guide for interviews regarding decision-making process for scaling up depression treatment in primary care, Chile, 2008

- Relevant antecedents

- Planning and design process and participation by the interviewees

- Critical factors for the implementation and subsequent scaling up of the program

- Key actors in the decision-making process and their role in the process

- Factors that influenced others to believe in the program's importance and costeffectiveness

- Scientific evidence considered influential

- Other critical factors and arguments that were considered important

- Political agreements and negotiations associated with the decision to implement and expand the program

- Resource allocation decisions

- Obstacles that emerged in the process

health disorders. Two large psychiatric morbidity surveys among the general population $(13,14)$ also confirmed the high prevalence of depression. Publications emanating from these surveys were used to continue advocating for more resources. Other studies showed that depression was also very common among primary care patients $(15,16)$, with one of these studies showing the highest prevalence rates among all participating countries. All interviewees mentioned that these studies had great resonance inside the $\mathrm{MoH}$ because they were based on local data.

Interviewees agreed that epidemiological studies can be useful, but for these to be influential, findings need to be actively brought to the attention of policymakers. Interviewees said that most policymakers have limited time to read scientific information and lack the depth of knowledge needed to understand the data, so any relevant findings need to be succinctly presented in an appropriate manner. There was general agreement that the Mental Health Unit at the $\mathrm{MoH}$ was particularly successful in translating scientific information into an acceptable format and leveraging available evidence effectively.
“... Unless there was a solid proposal supported with strong technical arguments, there was little that three or four psychiatrists in positions of influence could do. What was critical was that we had a good technical proposal to support politically ..."

(Head, Ministerial Cabinet)

One of the interviewees, the Head of the Mental Health Unit, noted that replacing the term "emotional problems" with "depression" was a major step forward: "The evidence had now a proper name: depression. All the important studies were using the term depression. We thought that we needed to change [too]."

Despite these consistent epidemiological findings, policymakers remained unconvinced that depression could be treated effectively. There was agreement among all six interviewees that a workable action plan needed to be presented to policymakers, since new programs are often better received when accompanied by a viable proposal designed to address a concisely identified problem. Interviewees identified two important events that helped: first, the visit of an international expert who presented results of treating depression through primary care in the United States of America; and second, a trial of cost-effectiveness of an improved treatment of depression through primary care in Chile (17).

Following the epidemiological surveys mentioned above, a randomized controlled trial of a program to improve the management of depressed women in the primary care setting showed highly encouraging results. Nearly $70 \%$ of the women receiving this improved treatment recovered by the 6-month mark, whereas only $30 \%$ had done so with the usual care (8).

Interestingly, interviewees acknowledged that the preliminary results of this trial in Chile had not been published by the time PNDTD was launched in 2004; however, there had been ongoing communication between the research team and those designing the program, facilitated by the fact that some of the researchers had worked or were working at the Ministry. Subsequent publications contributed to justifying the scaling up of the program to the national level in 2003.

According to the interviewees, a milestone was achieved when the $\mathrm{MoH}$ decided that depression would become the 
BOX 3. Summary of elements that led to the scaling up and sustainability of the National Depression Detection and Treatment Program (Programa Nacional de Diagnóstico y Tratamiento de la Depresión), Chile, 2008

\section{Scientific evidence \\ - To show that depression (or indeed any other pressing problem) is or should be an important public health priority and there are cost-effective solutions locally \\ - All information needed to be disseminated proactively, succinctly, quickly, and in a language understandable by policymakers.}

\section{Teamwork and leadership}

- A group of widely respected and politically "friendly" professionals joined together by a common goal, acting as leaders in a team effort

- Leaders capable of communicating effectively with decisionmakers

- Leaders with a capacity to detect emerging opportunities and react accordingly

- Leaders capable of negotiating political agreements at all levels

- Individuals with at least basic technical knowledge, capable of preparing and defending a solid proposal

- Trustworthy individuals capable of forming alliances with strategic partners and ensuring these new resources are on fixed contracts

\section{Strategic alliances}

- With key individuals occupying positions of political power at the Ministry of Health

- Across sectors with strategic partners

- That can persist over time

- With other units by which the program can be co-owned, especially those with more power within the organization

\section{Program institutionalization}

- Using well recognized models of health care delivery within the Ministry of Health

- Placing the program among other well established primary care programs

- Finding and introducing personnel (psychologists) widely available and at an affordable cost with potential to lead the program locally

- Fence ringing any new and essential financial resources

country's third highest health priority for 2002. The head of the Mental Health Unit stated that, ". . . thanks to the lobbying using the studies that had been done, we managed to get depression among the top health priorities."

In the early years of PNDTD, the $\mathrm{MoH}$ hired an academic institution to undertake a small scale and partial evaluation of the effectiveness of the program. The results showed high resolution at the primary care level and a reduction in referrals to secondary care (18). These preliminary and crude figures were seen as good support to request additional program funding. The Head of the Mental Health Unit stated, "When discussing budgets one needs to have something to support claims for funding ... having studies showing the effectiveness and efficiency of the intervention helped. ... People from other Ministries were impressed."

\section{Teamwork and leadership}

All interviewees agreed on the importance of a strong and effective leadership. However, the picture that emerged was not of a traditional leadership based on the capacity of a single individual, but that of an informal team of leaders acting in parallel at different levels and with a shared vision. Some individuals were singled out as having played more crucial roles than others though. For instance, some interviewees mentioned the important role played by the psychiatrist who led the design phase of the program.

Interviewees agreed that the leaders shared some common features; namely, they were: politically friendly and trustworthy; good at forming alliances; able to understand and apply technical information; and good communicators who could adapt their terminology to fit different situations.

\section{Strategic alliances}

All interviewees agreed that the strategic alliance between the Mental Health Unit and the Primary Care Division was vital. The Head of the Primary Care Division summed up this position with the statement, "At the time the proposal was made, we had already negotiated more resources for the coming year. We decided that we wanted to include this program in our budget. It was an excellent alliance with mental health because they had technical capacity and we had resources."

The Primary Care Division then accepted ownership and management of the program. Plus, other strategic alliances were formed outside the $\mathrm{MoH}$, most notably with the Ministry of Women and some universities. "Academics began to give us a lot of information ... which provided support for introducing the program. The Ministry of Women started a pilot primary care program with women.... We hired 94 teams distributed in different primary care centers," explained the Head of PNDTD.

\section{Program institutionalization}

All interviewees agreed that an element crucial to ensuring the program's sustainability was the gradual process of "institutionalization." Institutionalization was achieved by keeping the program aligned with well-known models of care and treatment protocols, similar to those of other ministerial programs; securing new and ring-fenced funding; and utilizing a minimal critical-mass of human resources.

The importance fitting well with traditional models already in use by the public health sector was widely acknowledged. The preferred approach had historically been of programs with universal coverage delivered through primary care.

These programs are not the product of enlightened minds; they are part of the natural evolution of the Chilean public health system. They follow the creation of the Mother and Baby programs in the '60s, deeply rooted in the primary care model. This was like a new step into a new territory, but following the same historical predicament or model. It is not necessarily novel, but a new development within a model that we were committed to for generations.

(Head, Primary Care Division)

Interviewees agreed that the program needed to be introduced as another Ministerial program, complying with all the regulations and ring-fenced funding.

In primary care, there have been many attempts at introducing mental health 
programs, but they did not have the financial or political backup. Some were able to function for a short time, but gradually faded away. This was different ... a program with a clinical protocol, financial and political support, itemized resource allocation ... this much money for psychologists, this much for medication ... it was a highly structured program from the technical and financial point of view ... Carefully worded contracts were signed and progress monitored constantly.

(Head, Primary Care Division)

All but two interviewees mentioned the importance of introducing psychologists into primary care. As part of the National Mental Health Program of 1993, a few psychologists had been introduced into primary care. When the PNDTD was scaled up, psychologists were hired in all primary care centers and became the program's cornerstone. The Head of the Mental Health Unit explained that with the scaling-up effort "those psychologists who were already working in primary care acquired a much more precise role in the clinics ... [and] we realized that ... psychologists could be hired for all clinics as key players."

According to the interviewees, hiring psychologists fitted well with other task-shifting experiences in primary care. The oversupply of psychologists facilitated this process. There was also agreement that it might not be possible to deploy psychiatrists to all primary care clinics.

We found a resource [psychologists] that was abundant in the country, at affordable costs, and that could make a substantial contribution in primary care. More importantly, psychologists were more likely to remain in primary care than doctors who often see primary care as a springboard to future specialization ... Our previous experience with nurses and midwives showed that many of them were better managers than were the doctors ... This is all connected with the history of public health in Chile ... in 1957 someone had the idea of hiring nurses to monitor the health of children, pediatricians protested loudly, but years later [they] were having a huge impact decreasing infant mortality ... something similar happened with midwives in programs to monitor the health of pregnant women ... all these successful programs were critical to justify the introduction of psychologists in mental health.

(Head, Primary Care Division)

With the implementation of PNDTD, responsibility for most patient care was transferred to primary care, away from specialized psychiatric services. This created friction and resistance from some groups, especially psychiatrists, who thought that psychologists were being given excessive clinical responsibilities in the management of depressed patients. One of their main concerns was that psychologists would eventually be allowed to prescribe medication and that they lacked the skills necessary for assessing cases of depression secondary to physical illness.

\section{DISCUSSION}

Several elements were identified as being important to the scaling up of PNDTD. Scientific evidence was regarded as important, but only if used effectively to support policies and programs with political backing. Other elements that appeared as equally, if not more, important were: effective teamwork and leadership; strong, strategic alliances; and an institutionalization process to secure long-term viability. These elements should not be seen in isolation, but rather as interacting in a time-dynamic way. For instance, effective leadership facilitated the formation of powerful strategic alliances, which in turn, helped to institutionalize the program within the ministerial framework. Some of these elements have played important roles in scaling up of other health programs $(19,20)$.

\section{Historical and political context}

An aspect which did not emerge from the interviews, but appeared in the documentation was the importance of the historical and political context, as demonstrated by other experiences in Latin America. For example, with the introduction of the Mexican Health Reform, information vital to its support was released just before the change of government, so that rather than inviting a defensive reaction, it became a powerful advocacy tool (21). A manual for scaling up suggests that it is better to initiate scaling up at the beginning, rather than at the end, of electoral cycles to allow more time for introducing change (22).

The authors of the present study consider the historical and political context surrounding the introduction of PNDTD in Chile to be important. An interviewee mentioned that during the military regime, serious problems accompanied by psychological repercussions, i.e., human rights abuses, had been ignored. With the return of democracy, these emerged as important new priorities, and teams, often led by mental health experts, were established to implement incipient programs to address them. Similarly, primary care, which prior to the military regime had been regarded as a continuation of local community initiatives, was once again given a much more prominent role by the $\mathrm{MoH}$ in the 1990s.

\section{The media}

Another issue relatively understated in the study's interviews was the importance of the media in policymaking. Throughout the 1990s, mental health issues remained a focus of interest in the media. In Chile, ministers are politicians, and as such, are sensitive to media pressure. Therefore, the authors surmise that initiatives that fit well with the prevailing political momentum are more likely to be implemented. In Chile and elsewhere, politicians seek out solutions that fit with their political agendas and values.

\section{Teamwork}

Teamwork, rather than individual leadership, figured prominently in this process, contrary to the commonly held view of individual leaders acting as champions of causes. One the interviewees even mentioned that too often initiatives have failed the test of time precisely because they were overly dependent on a single individual. Leadership is often mentioned as important in policymaking $(20,23)$, but there is often little clarity as to what kind of leadership is needed.

\section{Program institutionalization}

Another critical element was program institutionalization, which ensures its long-term viability. As with many other social and health policies, once a program becomes part of an organization, it is difficult to remove (24). Institutionalization can be a slow and gradual pro- 
cess, as seen in other LMIC settings (25). Programs similar to PNDTD, such as the maternal and child health program, have been highly successful, so this increased its attraction. Introducing highly innovative programs that depart greatly from traditional services is often difficult; improvements to well-established local programs are more likely to succeed. Similarly, programs that require extensive support structures or supplies for implementation are often considered "boutique" projects, with little prospect of long-term sustainability (22).

\section{Task-shifting}

One strategy that proved attractive and in line with traditional approaches in primary care was the task-shifting component (26), i.e., transferring responsibilities to psychologists who were widely available at an affordable price. Previous successful experiences with task shifting in primary care were important to facilitating the introduction of psychologists. Task shifting is sometimes presented as a second-class service for the more disadvantaged sectors of the population. However, the poor and depressed in Chile had virtually no mental health services prior to the introduction of psychologists in primary care. By the time PNDTD was in its pilot Angermeyer MC, Borges G, Bromet EJ, et al. Use of mental health services for anxiety, mood, and substance disorders in 17 countries in the WHO world mental health surveys. Lancet. 2007;370(9590):841-50.

2. Patel V, Garrison P, de Jesus MJ, Minas $H$, Prince M, Saxena S. The Lancet's series on global mental health: 1 year on. Lancet. 2008; 372(9646):1354-7.

3. Mangham LJ, Hanson K. Scaling up in international health: what are the key issues? Health Policy Plan. 2010;25:85-96.

4. Eaton J, McCay L, Semrau M, Chatterjee S, Baingana F, Araya R, et al. Scale up of services for mental health in low-income and middle-income countries. Lancet. 2011;378 (9802):1592-603.

5. Bass J, Neugebauer R, Clougherty KF, Verdeli $\mathrm{H}$, Wickramaratne P, Ndogoni L, et al. Group interpersonal psychotherapy for depression in rural Uganda: 6-month outcomes: randomised controlled trial. Br J Psychiatry. 2006; 188:567-73.

6. Rahman A, Malik A, Sikander S, Roberts C, Creed F. Cognitive behaviour therapy-based intervention by community health work- phase, those with state health insurance were more likely to see a psychologist than those with private insurance (27). Mental health needs in most LMIC are high; coupled with the small number of psychiatrists, there is no prospect that they alone will deliver all the needed care in the foreseeable future.

\section{Study limitations}

This study had some limitations. The number of interviews was small, but inevitable when exploring the views of only the top decisionmakers in the process. Additionally, there are always omissions in the documentation available for review and the historical context is open to interpretation.

\section{Conclusions}

Challenges continue after scaling up, and resource constraints are always testing the balance between extending coverage and maintaining quality (3). Addressing the opportunity costs inherent to targeted programs is another challenge since they often require that resources be shifted from other programs and priorities. Nonetheless, some of the best known examples of scaling up are vertical, targeted programs, such as child immunization programs.

\section{REFERENCES}

ers for mothers with depression and their infants in rural Pakistan: a cluster-randomised controlled trial. Lancet. 2008;372: 902-9.

7. Patel V, Weiss HA, Chowdhary N, Naik S, Pednekar S, Chatterjee S, et al. Effectiveness of an intervention led by lay health counsellors for depressive and anxiety disorders in primary care in Goa, India (MANAS): a cluster randomised controlled trial. Lancet. 2010;376(9758):2086-95.

8. Araya R, Rojas G, Fritsch R, Gaete J, Rojas M, Simon G, et al. Treating depression in primary care in low-income women in Santiago, Chile: a randomised controlled trial. Lancet. 2003;361(9362):995-1000.

9. Araya R, Alvarado R, Minoletti A. Chile: an ongoing mental health revolution. Lancet. 2009;374(9690):597-8

10. Forman J, Dmaschroder L. Qualitative content analysis. In: Jacoby L, Siminoff L, eds. Empirical methods for bioethics: A primer. Oxford: JAI Press; 2008.

11. Denzin NK. Strategies of multiple triangulation. The research act: A theoretical Introduction to sociological methods. New York: McGraw Hill; 1989.
A review of the literature produced a relevant and an important finding: it is often the case that after a mental health program is introduced, there is often no further evaluation (4). PNDTD is such a case-there have not been any adequate evaluations since its inception other than a small scale and partial study (18). The lack of evaluations of health programs is the norm rather than the exception in LMIC. Unfortunately, if interventions are not measured and evaluated, it is difficult to show any return on investment and to justify their continuation.

In summary, this study found that scientific evidence can be important in making the decision to scale up programs, but other factors are probably more salient, including effective leadership; strong strategic alliances; and a swift institutionalization process that secures program sustainability. Another potent message arising from this and similar studies (20) is that policy changes can take many years to come to fruition. These are two powerful reasons to support the push to begin scaling up mental health programs now. The PNDTD is a unique example of scaling up mental health services and provides a great opportunity to develop feasible, but effective evaluation methods that may be useful to other countries with similar socioeconomic challenges.
12. Ministerio de S. Estudio de carga de enfermedad. Santiago, Chile: Ministerio de Salud, 1996.

13. Araya R, Rojas G, Fritsch R, Acuna J, Lewis G. Common mental disorders in Santiago, Chile: prevalence and socio-demographic correlates. Br J Psychiatry. 2001;178:228-33.

14. Vicente B, Kohn R, Rioseco P, Saldivia S, Baker C, Torres S. Population prevalence of psychiatric disorders in Chile: 6-month and 1-month rates. Br J Psychiatry. 2004;184:299-305.

15. Araya R, Wynn R, Leonard R, Lewis G. Psychiatric morbidity in primary health care in Santiago, Chile. Preliminary findings. Br J Psychiatry. 1994;165:530-3.

16. Sartorius N, Ustun TB, Costa e Silva JA, Goldberg DP, LeCrubier Y, Ormel J, et al. An international study of psychological problems in primary care. Arch Gen Psychiatry. 1993;50:819-24.

17. Araya R, Flynn T, Rojas G, Fritsch R, Simon G. Cost-effectiveness of a primary care treatment program for depression in low-income women in Santiago, Chile. Am J Psychiatry. 2006;163(8):1379-87.

18. Alvarado R, Vega J, Sanhueza G, Muñoz MG. Evaluación del Programa para la De- 
tección, Diagnóstico y Tratamiento Integral de la Depresión en atención primaria en Chile. Rev Panam Salud Publica. 2005;18(4/5): 278-86.

19. McCannon CJ, Berwick D, Massoud MR. The science of large-scale change in global health. JAMA. 2007;298(16):1937-9.

20. Berwick D. Lessons from developing nations on improving health care. BMJ. 2004;328: 1124-9.

21. Knaul FM, Arreola-Ornelas H, MedezCarniado O, Bryson-Cahn C, Barofsky J, Maguire $\mathrm{R}$, et al. Health system reform in Mexico 4: Evidence is good for your health system: policy reform to remedy catastrophic and impoverishing health spending in Mexico. Lancet. 2006;368:1828-41.
22. World Health Organization. Practical guidance for scaling up health service innovations. Geneva: WHO; 2009.

23. Medlin CA, Chowdhury M, Jamison DT, Measham AR. Improving the health of populations: lessons of experience. In: Jamison DT, Breman JG, Measham AR, eds. Disease Control Priorities in Developing Countries. New York: Oxford University Press; 2006.

24. Gwatkin RD. Reducing health inequalities in developing countries In: Detels R, McEwen J, Beaglehole R, Tanaka H, eds. Oxford Textbook of Public Health; 2002. Pp. 1791-809.

25. Evans T, Nishtar S, Atun R, Etienne C. Scaling up research and learning for health systems: time to act. Lancet. 2008;372:1529-31.
26. McPake B, Mensah K. Task shifting in health care in resource-poor countries. Lancet. 2008; 372:870-1.

27. Araya R, Rojas G, Fritsch R, Frank R, Lewis G. Inequities in mental health care after health care system reform in Chile. Am J Public Health. 2006;96(1):109-13.

Manuscript received on 17 August 2011. Revised version accepted for publication on 22 May 2012

RESUMEN En Chile, el Programa Nacional de Diagnóstico y Tratamiento de la Depresión (PNDTD) en atención primaria constituye un raro ejemplo de programa de salud mental basado en la evidencia ampliado al nivel nacional en un país de ingresos me-

Enseñanzas derivadas de la ampliación de un programa para el tratamiento de la depresión en atención primaria en Chile

Palabras clave dios o bajos. Con este estudio retrospectivo cualitativo se buscó conocer más a fondo la forma en que los responsables de las políticas tomaron la decisión de ampliar los servicios de salud mental al nivel nacional e investigar los elementos, contextos y procesos que facilitaron la decisión de implementar y mantener el PNDTD. Entre agosto y diciembre de 2008, seis informantes clave seleccionados mediante muestreo intencional llevaron a cabo entrevistas en profundidad semiestructuradas. Los entrevistados eran funcionarios de alto nivel del Ministerio de Salud directamente involucrados en la decisión de ampliar el programa.

Los resultados arrojaron cuatro elementos fundamentales para el proceso de toma de decisiones: las pruebas científicas, el trabajo en equipo y el liderazgo, las alianzas estratégicas y la institucionalización del programa. Los cuatro elementos contribuyeron a la creación de consensos, la obtención de financiamiento, la captación de recursos y la obtención de un apoyo duradero por parte de los responsables de las políticas. Además, la revisión de la documentación disponible llevó a los autores a considerar al contexto sociopolítico y el uso de los medios factores importantes.

Mientras se siguen acumulando datos de investigación sobre la eficacia de los servicios de salud mental en la atención primaria, los países con ingresos medios y bajos deben comenzar el largo proceso de ampliación incorporando los elementos que condujeron a la toma de decisiones y la implementación del PNDTD en Chile.

Servicios comunitarios de salud mental; depresión; prestación de atención de salud; salud mental; Chile. 